\title{
A REVIEW
}

\section{Role of soil microbiota in soil fertility}

\author{
Monalisa Dhall ${ }^{1}$, Bandana Mishra ${ }^{1}$, Saurav Barman ${ }^{2}$ and Praveen Boddana* \\ Department of Plant Pathology, M.S. Swaminathan School of Agriculture, Centurion University of Technology \\ and Management, R Sitapur, Paralakhemundi, Gajapati (Odisha) India \\ (Email: bpraveen@cutm.ac.in)
}

\begin{abstract}
Long- term adoption of total agricultural approach which negatively influences the soil prolificacy, soil microbiome and may compromise the feature and amount of crop mass production. In agriculture, soil is a critical part, in which the original sources of nutrients for grow crops and the microorganisms is very important to improve soil texture or soil health for healthy growing crops. Soil microbiota are an energetic component of soil and showed varieties useful activities in the soil system. Soil richness is the characteristic limit of a soil to give the fundamental plant supplements in sufficient sums and legitimate extents for plant development. There is an enormous chance to upgrade soil ripeness through microorganisms, as organisms are "inherent" soil controllers and impetuses adding to reusing of supplements into accessible inorganic structures and give early admonition of land corruption. The core interest of this part is on the possibility of utilizing organisms as decomposers of (cellulose, protein and lignin), formers (humus, nitrate and nitrite), nitrogen fixers, ammonifiers, oxidizers (iron, hydrogen and sulfur), phosphorus solubilizers and denitrifiers. In this specific circumstance, the components viz., natural toxins and environmental change that limit the improvement of soil richness. Today's, there is great trial for the agricultural system in which growing the human population is a great problem in the land breakdown and decrease the microbial population that's why enhance the soil fertility and plant growth rate decreases. Therefore, in this review we describe the benefits of soil microbiota to maintain soil fertility.
\end{abstract}

Key Words : Soil prolificacy, Soil microbiome, Ammonifier, Oxidisers, Solubulizer, Denitrifiers

View Point Article : Dhall, Monalisa, Mishra, Bandana, Barman, Saurav and Boddana, Praveen (2021). Role of soil microbiota in soil fertility. Internat. J. agric. Sci., 17 (2) : 729-739, DOI:10.15740/HAS/IJAS/17.2/729-739. Copyright@2021: Hind Agri-Horticultural Society.

Article History : Received : 03.03.2021; Accepted : 19.03.2021

\footnotetext{
* Author for correspondence

${ }^{1}$ Department Of Botany, School of Applied Science, Centurion University of Technology and Management, R Sitapur, Paralakhemundi, Gajapati (Odisha) India

${ }^{2}$ Department of Soil Science and Agricultural Chemistry, M.S. Swaminathan School of Agriculture, Centurion University of Technology and Management, R Sitapur, Paralakhemundi, Gajapati (Odisha) India
} 